\title{
Color correspondence of different brands and composite resin systems in relation to the Vita Classical scale through spectrophotometry
}

Diogo de Azevedo Miranda ${ }^{1 *}$, Yuri Lobo Valle Marçal ${ }^{2}$, Fernanda Pícoli Proba ${ }^{2}$, Thayane Kethlin Pimenta Moreira ${ }^{2}$, Laura Nobre Ferraz ${ }^{3}$ and Flávio Henrique Baggio Aguiar ${ }^{4}$

${ }^{1}$ Adjunct Professor of Faculty of Medical Sciences and Health of Juiz De Fora, Brazil

${ }^{2}$ Student, Dental of Faculty of Medical Sciences and Health of Juiz De Fora / SUPREMA, Brazil

${ }^{3}$ Student, Department of Restorative Dentistry, Operative Dentistry Area, Piracicaba Dental School, University of Campinas, Piracicaba, São Paulo, Brazil

${ }^{4}$ Full Professor Department of Restorative Dentistry, Operative Dentistry Area, Piracicaba Dental School, University of Campinas, Piracicaba, São Paulo, Brazil

\begin{abstract}
Introduction: The color matching between aesthetic materials and dental structure is certainly the parameter most used by patients to evaluate the quality of the aesthetic treatments performed, influencing decisively the judgment of professional competence and the degree of patient satisfaction at the end of the treatment.

Objective: To identify among the composite resins, which present greater color matching with the Vita Classical scale.

Method: Six groups were formed; the Tetric N-Flow ${ }^{\circledR}$ color A1 resin was used as light control and the Tetric N-Flow ${ }^{\circledR}$ A4 color as dark control and 4 A2D color resins (Oplais, Empress Direct, Esthelite and Z350). For each material, ten specimens were prepared. The reading of each test specimen was performed through a spectrophotometer and then annotated the CIELab standard, in addition to reading through the hue and chroma. A visual evaluation was performed between 4 evaluators so that they could check the resins against the light and dark patterns.
\end{abstract}

Results: The tonality of each specimen presented a low percentage of correspondence, in relation to the A2 color of the Vita scale. The $\Delta \mathrm{E}$ values of the groups and the A2 range of the Vita scale were submitted to statistical analysis with 5\% significance. ANOVA resulted in statistically significant differences for all sample groups ( $\mathrm{p}<0.05)$. The Tukey test showed no color match between the analyzed materials and the reference hue of the Vita scale.

Conclusion: there was no color match with the reference A2 of the Vita scale; the differences of composition and manufacturers result in colors that are close but different.

\section{Introduction}

The color matching between aesthetic materials and the dental structure is certainly the parameter most used by the patients to evaluate the quality of the aesthetic treatments performed, influencing decisively the judgment of the professional competence and the degree of satisfaction of the patient at the end of the treatment. So much so that the term biomimetics has recently been introduced as a reference for quality of procedure, technique and / or restorative material [1].

From the point of view of optical physics, human teeth are considered as a heterogeneous, fluorescent and polychromatic crystalline structure, consisting of a sequence of elements that present different levels of translucency and opacity $[1,2]$. This varied constitution causes the color of the tooth to be determined by the conjunction of optical phenomena of reflection, transmission, dispersion, internal scattering and selective filtering, associated with the spontaneous emission of wavelengths other than incident light (fluorescence), according to Chu, Devigus and Mieles [3], determines the metameric behavior of dental structure under different lighting sources.

Although there has been an excellent evolution in recent years regarding composition, color availability, transparency levels and effects, these improvements have in some way improved the physical, mechanical and optical properties of the composite resins, but due to the inherent material, the composite resins still have lower biomimetic potential because they do not constitute a crystalline structure and because of the reduction of translucency, opacity, effects and absence or presence of fluorescence of many restorative systems [4-6]. These characteristics alone make the color matching between the composite resins and the tooth structure difficult to obtain.

The best-selling brands of composite resins since 1980 have adopted the ABCD standard of the Vita Classical color scale as a classification of the shades of their restorative materials. Although this standardization suggests that resins of the same shade can be used as substitutes for each other, clinical observations and laboratory studies have shown that the color matching between different composite resin trademarks is low,

*Correspondence to: Diogo de Azevedo Miranda, Rua Sampaio 330/602, Granbery, Juiz de Fora, Minas Gerais 36010-360, Brazil, E-mail: diogoodonto@yahoo.com.br

Key words: composite resin, classical vita scale, spectrophotometer

Received: November 12, 2018; Accepted: November 29, 2018; Published: December 03, 2018 
as well as the correspondence between the resins and the scale Vita Classical is not expected.

This explains the clinical difficulties regarding color selection and the high index of dissatisfaction with the aesthetic end result of the restorations. Thus, the objective of the present work was to identify among the composite resins, which have the highest color matching with the Vita Classical scale. And, also, to verify the possibility of clinical substitution of one resin for another, as a function of the color matching.

\section{Materials and methods}

\section{Experimental design}

The factors studied were the Estelite $\Sigma$ Quick composites (Tokuyama Dental), Opallis (FGM), Z350 XT (3M) and EmpressDirect (IvoclarVivadent). TetricN-Flow resins in A4 and A 1 colors, respectively, were used as dark and light standard. The response variables were the color dimensions within the CIE system $L^{*} a^{*} b^{*}$, on the top surface of each test specimen. For standard control, the Vitta Classical A2 color palette was used.

\section{Preparation of test specimens}

The test specimens were made by a single operator, according to ISO 4049 specifications. All specimens were made under the same conditions of temperature, illumination and relative humidity and then divided into four groups $(n=10)$, taking into account the factors under study, which are the four commercial brands of composite resins.

A polyester strip was placed on a glass plate and then a $6 \mathrm{~mm}$ diameter, $1 \mathrm{~mm}$ thick Teflon cylindrical die was placed. The resins were inserted in a single increment in the matrix and on the assembly was placed another polyester strip under pressure of an acrylic plate under a weight, so that a material compression occurred and the excess could be extravasated.

After this step, photoactivation was carried out for 40 s using the Radii Cal light curing apparatus (SDI) directly against the specimen. The light intensity (mean irradiance) emitted by the photopolymerizer was $1085 \mathrm{~mW} / \mathrm{cm}^{2}$ previously measured by the Ecel RD-7 radiometer.

After polymerization, the specimens were removed from the matrix and then stored in dark containers, so that no external light interference could alter the quality of the photoactivation until the tests were performed.

\section{Evaluation by spectrophotometer}

The clinical spectrophotometer (Vita EasyShade - Vident-Brea, CA, USA) was used in this evaluation, where three color registers were sent to each of the test specimens, in addition to the A2 reference of the Vita Classical scale. Initially, the spectrophotometer was calibrated and the reading probe was placed perpendicular and fully supported on the surface of the specimens, and the light beam was triggered from the trigger positioned on the back of the reading probe. The reading was done inside a light chamber, with ambient and controlled light. On the instrument screen, it was possible to visualize the results of the Vita Classical scale and the values of $\mathrm{L}^{*}, \mathrm{a}^{*}$ and $\mathrm{b}{ }^{*}$, which were recorded in specific worksheets for further evaluation. The data of the visual comparative evaluation were qualitatively analyzed according to the percentage of correspondences observed and the agreement between examiners [7].

The results of the spectrophotometry were objectively evaluated according to the values of hue difference $(\Delta \mathrm{E})$, obtained according to the equation proposed by the Commission Internationaled 'Eclairage (CIE) 2, in 1976:

$\Delta \mathrm{E}=\sqrt{(L * 1 L * 2)^{2}+(a * 1 a * 2)^{2}+(b * 1 b * 2)^{2}}$ Where, $\mathrm{L}^{*}=$ variation of luminosity with variation from 0 to $100, \mathrm{a}^{*}=$ blue / yellow axis variation, $\mathrm{b}^{*}=$ red / green axis variation. In addition, spectrophotometry results were also analyzed according to the tonality of the Vita Classical reference range [7].

\section{Visual comparison}

For the visual comparative evaluation, the specimens were randomly distributed in six clusters, each containing ten specimens from each experimental group (Figure 1). Four non-calibrated volunteers participated in this stage, who were asked to sort the specimens from the lightest to the darkest, grouping in that order the specimens of similar shades according to their personal criteria. The individual results of each classification were recorded in spreadsheets prepared in Microsoft Excel @ software.

\section{Results}

\section{Statistical analysis}

After the exploratory analysis of the data was applied an analysis of variance (ANOVA) "oneway" and Tukey test comparing the $\Delta \mathrm{E}$ between the four resins. Next, a t-test for a mean was applied, comparing the $\Delta \mathrm{E}$ of each resin with zero, to evaluate the color matching of the tested resins with the vita $\mathrm{A} 2$ scale. Resins with $\Delta \mathrm{E}$ closer to zero present greater similarity between the scales. The analyzes were performed in the R program with significance level of $5 \%$.

\section{Spectrophotometer}

The four resins presented mean $\Delta \mathrm{E}$ significantly higher than zero (vita A2 scale), $\mathrm{p}<0.05$, Table 1 and Figure 2. The Estelite A2D resin presented significantly lower mean $\Delta \mathrm{E}$ than the others $(\mathrm{p}<0.05)$ and the Opallis A2D and Z350 A2D resins presented significantly higher mean values than the others $(\mathrm{p}<0.05)$.

$$
\begin{aligned}
& \text { p-value (between resins) }<0.0001 \\
& \text { p-value (resin } 1 \text { compared to zero) })<0.0001 \\
& \text { p-value (resin } 2 \text { comparing with zero) })<0.0001 \\
& \text { p-value (resin } 3 \text { comparing with zero) }<0.0001 \\
& \text { p-value (resin } 4 \text { compared to zero) }<0.0001
\end{aligned}
$$

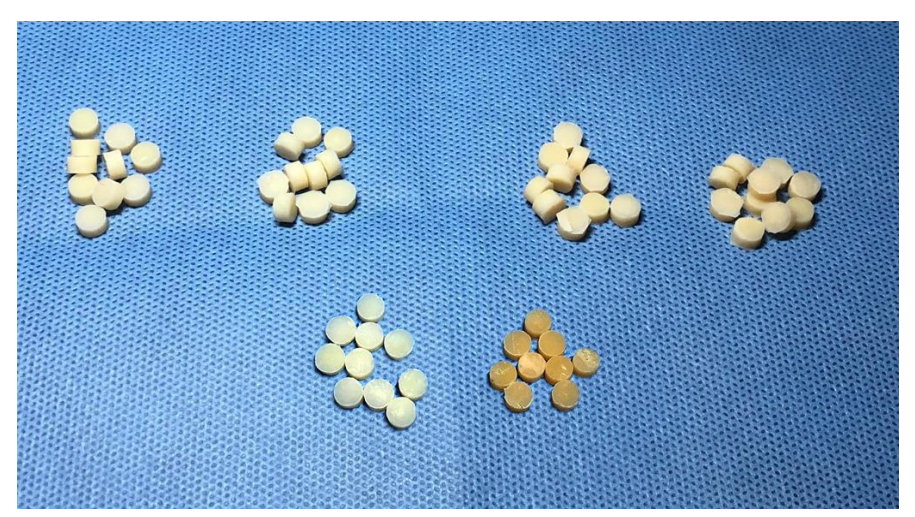

Figure 1. Analysis clusters, each containing ten specimens from each experimental group 
Table 1. Composition of each composite resin according to its brand and color

\begin{tabular}{|c|c|c|}
\hline Composite Resin & Color & Composition \\
\hline $\mathrm{Z} 350 \mathrm{XT}$ & $\mathrm{A} 2 \mathrm{D}$ & $\begin{array}{l}\text { Ceramics treated with silane, bisphenol A diglycidyl dimethacrylate ether (BIS-GMA), bisphenol A polyethylene glycol diéterdemetacrilato } \\
\text { (BIS-EMA), silica,silane treated, zirconium silica oxide treated with silane, diuretanodimetacrilato,dimetacrilatopolietilenoglicol dimethacrylate, } \\
\text { triethylene glycol ( TEG-DMA), 2,6-di-tert-butyl-p-cresol (BHT) and pigments. }\end{array}$ \\
\hline EmpressDirect & $\mathrm{A} 2 \mathrm{D}$ & $\begin{array}{l}\text { The monomer matrix is composed of dimethacrylates }(20-21.5 \% \text { by weight, opalescent color } 17 \% \text { by weight). The particles are composed } \\
\text { of barium glass,ytterbium trifluoride, mixed oxides, silicon dioxide and copolymer ( } 77.5-79 \% \text { by weight, opalescent color } 83 \% \text { by weight). } \\
\text { Additional content: additives, initiators, stabilizers and pigments }(<1.0 \% \text { by weight). The total content of inorganic particles is } 75-79 \% \text { by weight } \\
\text { or } 52-59 \% \text { by volume (opalescent color } 60.5 \% \text { by weight or } 45 \% \text { by volume). The size of the inorganic particles is between } 40 \mathrm{nmand} 3 \mu \mathrm{m}, \\
\text { with an average particle size of } 550 \mathrm{~nm} \text {. }\end{array}$ \\
\hline Tetric N- flow & A1 A4 & $\begin{array}{l}\text { It contains } 36 \% \text { by weight of dimethacrylates (including TEGDMA), } 63 \% \text { by weight of particles (barium oxide, ytterbium trifluoride, highly } \\
\text { dispersed silica and mixed oxides) and } 1 \% \text { by weight of pigments, catalysts and stabilizers. The total inorganic particles are } 39 \% \text { by volume. The } \\
\text { size of the inorganic particles ranges from } 40 \mathrm{~nm} \text { to } 3000 \mathrm{~nm} \text {. }\end{array}$ \\
\hline Estelite $\Sigma$ Quick & $\mathrm{A} 2 \mathrm{D}$ & The monomer matrix contains Bis-GMA and triethylene glycol dimethacrylate \\
\hline Opallis & $\mathrm{A} 2 \mathrm{D}$ & $\begin{array}{l}\text { Monomer Bis-GMA (bisphenol A di-Glycidyl Methacrylate), BisEMA (bisphenol Aethoxylate di-Glycidyl Methacrylate), TEGDMA (Triethylene } \\
\text { glycoldimethacrylate), UDMA (urethane dimethacrylate), camphorquinone, co-initiatorand silane. Inactive Ingredients: barium aluminosilicate } \\
\text { glass, silanized silicate,silicas and pigments. }\end{array}$ \\
\hline
\end{tabular}

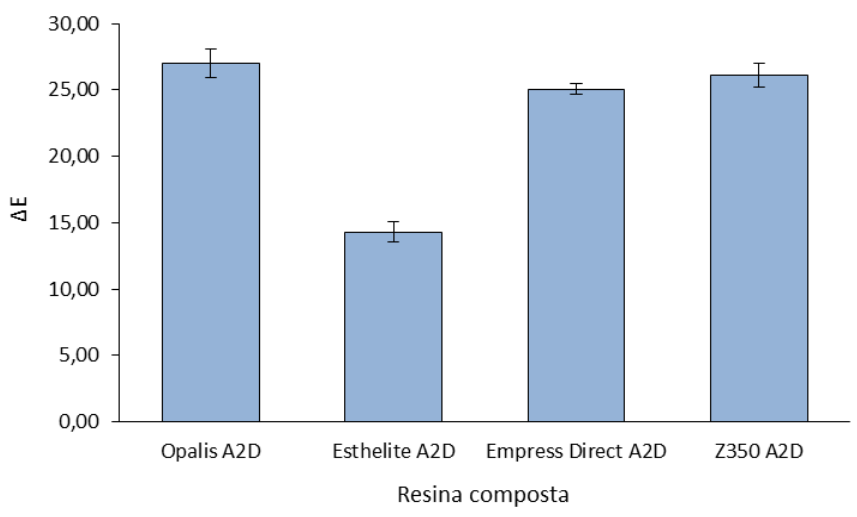

Figure 2. Mean (standard deviation) of $\Delta \mathrm{E}$ as a function of composite resin

\section{Discussion}

Color matching is defined as not perceiving the presence of the restorative material or tolerance and acceptance by the patient and the dentist in relation to the level of color difference [8] that occurs between the restoration and the dental structure [9-11].

The color difference $(\Delta \mathrm{E})$ of two objects can then be determined by comparing the differences between the respective coordinates of values for each sample [8]. In this study, the color matching of four composite resin commercial brands was evaluated in relation to the Vita Classical scale and the visual comparison with two control tonalities (Tetric $\mathrm{N}$-flowA1 and A4).

According to the results obtained, the resin that obtained the highest variation value of $\Delta \mathrm{E}$ was Opallis $\mathrm{A} 2 \mathrm{D}$ (27.02), while the resin with the smallest variation was Estelite A2D (14,31). The EmpressDirect, Z350 and Opallis brands obtained close results (25.06, 26.15 and 27.02, respectively), with Z350 and Opallis having a higher variation of the analyzed standard.

The results of this study also showed that, when analyzing the respective types of composite resin, through the spectrophotometer (Table 2), no composite resin tested was similar to the Vita Scale. Only the dark pattern (Tetric N-Flow A4) was matched by its corresponding color on the Vita Scale. Analyzing the other resins, it was observed that there was a considerable difference of color in relation to the color of the Vita Classical Scale, where the Opallis, Estelite, Z350 resins had similar color to the dark (Tetric N-Flow A4), that is, the The respective resins were classified as A4 (Vita Classical Scale) by reading the spectrophotometer. According to Table 3, Empress Direct resin also shows a similar result to the clear pattern. Both resins (Empress and Tetric N-Flow A1) were classified as B3 (Vita Classical Scale).

The analysis of the data obtained with Vita EasyShade ${ }^{\triangleright}$ showed a positive correspondence between the nominal tonality and the instrument classification only for the dark pattern (Tetric N-Flow A4). All test specimens A2, as well as clear control A1, were classified as A4 and B3. What can explain this fact is the translucency of the composite resins, which allows passage of part of the incident light and consequently, alter the reading of the spectrophotometer, since such equipment was developed to analyze the light that returns from the analyzed object, after the reading light trip [7,9].

As in the study of Dantas, et al. [7], the evaluators unanimously were able to visually distinguish the light and dark pattern (TetricA1 and A4). However, the resins tested (A2) were not visually differentiated among them [7].

Color evaluation by visual comparisons is not considered a reliable method, since human perception of color is complex and encompasses subjective and objective phenomena [10]. Such methods of evaluation are susceptible to errors arising from perceptual inconsistencies over time $[11,12]$.

During the daily clinic, it is observed that the $\Delta \mathrm{E}$ values that determine the limits of tolerance and acceptance of the differences do not enter into a consensus $[1,8,13,14]$. A range of 3.3 units of $\Delta \mathrm{E}$ was considered by Russel, Gulfraz and Moss 10 as acceptable for samples in composite resin, while the United States Public Health Service (USPHS) uses the limit of 3.7 units of $\Delta \mathrm{E}$ to determine the lack of color matching and the need for replacement of aesthetic restorations [5]. the 
Table 2. Mean, standard deviation, minimum value, first quartile, median, third quartile and maximum value of $\Delta \mathrm{E}$ as a function of composite resin

\begin{tabular}{|c|c|c|c|c|c|c|}
\hline Composite resin & Average & Standard deviation & Minimum & First quartile & Medium & Third quartile \\
\hline Opallis A2D & $* 27.02 \mathrm{a}$ & 1.08 & 25.05 & 26.61 & 27.30 \\
\hline Est elite A2D & $* 14.31 \mathrm{c}$ & 0.77 & 13.28 & 13.89 & 27.81 \\
\hline EmpressDirect A2D & $* 25.06 \mathrm{~b}$ & 0.42 & 24.45 & 24.68 & 14.16 \\
\hline Z350 A2D & $* 26.15 \mathrm{a}$ & 0.89 & 25.03 & 25.62 & 25,20 \\
\hline
\end{tabular}

Means followed by distinct letters differ from each other $(\mathrm{p} \leq 0.05)$. ${ }^{*}$ It differs from zero $(\mathrm{p} \leq 0.05)$

Table 3. Color interpretation according to the spectrophotometer, using the hue / chroma pattern

\begin{tabular}{|c|c|c|}
\hline Brand & Color Described By Brand & Read Spectrophotometer \\
\hline Opallis & A2D & A4 \\
\hline Estelite & A2D & \\
\hline EmpressDirect & A2D & \\
\hline Z350 & A2D & \\
\hline Tetric N- flow & A1 & \\
\hline Tetric N- flow & A4 & B3 \\
\hline
\end{tabular}

mimicking of dental structures, the clinically acceptable color difference limit is $3.7 \Delta \mathrm{E}$ units. A mean of $\Delta \mathrm{E}$, above 3.7, becomes visible to the naked eye $[5,14,15]$.

According to the study by Téo, et al. [14]. When the $\Delta \mathrm{E}$ of two colors is less than 1 unit $(\Delta \mathrm{E}<1)$, the colors are considered equal. When $\Delta \mathrm{E}$ is between 1 and 2 units, two or more observers can often make correct judgments about the difference between colors. If the value of $\Delta \mathrm{E}$ is greater than 2 units, all observers can detect the differences in color $[5,12,14]$. In view of this reasoning we can say that the Opallis, Z350 and EmpressDirect resins have very similar colors between them, where the largest variance of $\Delta \mathrm{E}$ between the marks was 1.96. This explains why the evaluators have difficulties in the visual comparison of test specimens A2 [16].

\section{Conclusion}

From the results found in this study we can conclude that:

- The result of this test showed that none of the materials tested showed color matching with reference A2 of the Vita Classical scale.

- It is not possible to establish the possibility of clinical substitution of one resin for another, depending on the color matching; the methods of analysis resulted in distinct classification and low correlation among themselves.

- The studied composite A2 resins have, in their majority, tonalities close, but, statistically, different from each other.

- The Estelite resin presented the highest similarity, although it presented values of $\Delta \mathrm{E}$, which was statistically high.

- The two evaluation methods correctly identified the control resin A4 as distinctly different from the other A2 resin.

\section{Clinical relevance}

Evaluate if there is color matching between resins of the same color with the Vita Classical scale.

\section{References}

1. Douglas RD, Steinhauer TJ, Wee AG (2007) Intraoral determination of the tolerance of dentists for perceptibility and acceptability of shade mismatch. J Prosthet Dent 97 : 200-208. [Crossref]

2. Hassel AJ, Koke U, Schimitter M, Beck J, Rammelsberg P (2005) Clinical effect of different shade guide systems on the tooth shades of ceramic-veneered restorations. Int J Prosthodont 18: 422-426.
3. Chu SJ, Devigus A, Mieleszco A (2004) Fundamentals of color - shade matching and communication in esthetic dentistry. New York: Quintessence Publishing.

4. Lagouvardos PE, Diamanti H, Polyzois G (2004) Effect of individual shades on reliability and validity of observers in color matching. Euro J Prosthodont Restor Dent 12: $51-56$.

5. Johnston WM, Kao EC (1989) Assessment of appearance match by visual observation and clinical colorimetry. J Dent Res 68: 819-822. [Crossref]

6. Kim BJ, Lee YK (2009) Influence of the shade designation on the color difference between the same shade-designated resin composites by the brand. Dent Mater 25: 1148-1154. [Crossref]

7. Dantas AAR, Florez FLE, Campos EA, Andrade MF, Saad JRC, et al. (2011) Color matching of different brands and composite resin systems in relation to the vitaclassical scale. RPG Rev Post Grad 18: 45-51

8. Douglas RD, Brewer JD (1998) Acceptability of shade differences in metal ceramic crowns. J Prosthet Dent 79: 254-260. [Crossref]

9. Masotti AS, Onófrio AB, Conceição EM Spohr AM (2007) Uv -vis spectrophotometric direct transmittance analysis of composite resins. Dental Materials 23: 724-730.

10. Russell MD, Gulfraz M, Moss BW (2000) In vivo measurement of colour changes in natural teeth. J Oral Rehabil 27: 786-792. [Crossref]

11. Johnston WM, Kao EC (1989) Assessment of appearance match by visual observation and clinical colorimetry. $J$ Dent Res 68: 819-822. [Crossref]

12. Ruyter IE, Nilner K, Moller B (1987) Color stability of dental composite resin materials for crown and bridge veneers. Dent Mater 3: 246-251.

13. Douglas RD, Steinhauer TJ, Wee AG (2007) Intraoral determination of the tolerance of dentists for perceptibility and acceptability of shade mismatch. J Prosthet Dent 97 : 200-208. [Crossref]

14. Téo TB, Takahashi MK, Gonzaga CC, Lopes MGK (2010) Evaluation, after bleaching, of the color change of bovine teeth immersed in solutions with high potential of pigmentation. Rev Sul-Bras Odontol 7: 401-405.

15. Seghi RR, Hewlett ER, Kim J (1989) Visual and instrumental colorimetric assessments of small color differences on translucent dental porcelain. J Dent Res 68: 1760-1764. [Crossref]

16. Seghi RR, Johnston WM, O'Brien WJ (1989) Performance assessment of colorimetric devices on dental porcelains. J Dent Res 68: 1755-1759. [Crossref]

Copyright: (C)2018 de Azevedo Miranda D. This is an open-access article distributed under the terms of the Creative Commons Attribution License, which permits unrestricted use, distribution, and reproduction in any medium, provided the original author and source are credited. 